\title{
Papers
}

\section{Cost effectiveness analysis of screening for sight threatening diabetic eye disease}

\author{
Marilyn James, David A Turner, Deborah M Broadbent, Jiten Vora, Simon P Harding
}

\begin{abstract}
Objective To measure the cost effectiveness of systematic photographic screening for sight threatening diabetic eye disease compared with existing practice.

Design Cost effectiveness analysis

Setting Liverpool.

Subjects A target population of 5000 diabetic patients invited for screening.

Main outcome measures Cost effectiveness (cost per true positive) of systematic and opportunistic

programmes; incremental cost effectiveness of replacing opportunistic with systematic screening. Results Baseline prevalence of sight threatening eye disease was $14.1 \%$. The cost effectiveness of the systematic programme was $£ 209$ (sensitivity $89 \%$, specificity $86 \%$, compliance $80 \%$, annual cost $£ 104996$ ) and of the opportunistic programme was $£ 289$ (combined sensitivity 63\%, specificity 92\%, compliance $78 \%$, annual cost $£ 99981$ ). The incremental cost effectiveness of completely replacing the opportunistic programme was $£ 32$. Absolute values of cost effectiveness were highly sensitive to varying prevalence, sensitivity and specificity, compliance, and programme size.

Conclusion Replacing existing programmes with systematic screening for diabetic eye disease is justified.
\end{abstract}

\section{Introduction}

Various methods of screening for diabetic eye disease have been tested in recent years, ${ }^{1-12}$ but few studies have produced meaningful cost effectiveness data. A three centre study commissioned by the Department of Health reported relatively high costs per case of diabetic eye disease detected. ${ }^{12}$ Similar data are also available from the United States. ${ }^{5}$ The Department of Health study was undermined by suboptimal screening methods, and both studies disregarded the effect of pre-existing opportunistic screening on cost effectiveness. Foulds et al studied the potential savings of systematic screening, but the cost effectiveness data are difficult to verify in the absence of sensitivity data. ${ }^{13}$ Mathematical modelling has also been used to study the potential economic benefits of screening. ${ }^{4}{ }^{14}$

Nationally coordinated screening of diabetic patients for sight threatening eye disease is being con- sidered as part of the national service framework on diabetes, which is due to be published in spring 2001, and an economic evaluation of a programme with high sensitivity and specificity and known prevalence and compliance is therefore urgently needed. ${ }^{15}$ The Liverpool diabetic eye study was established in 1991 to investigate the efficacy of primary care based photographic screening for sight threatening eye disease and to set up a systematic service replacing the existing opportunistic programme. We present a detailed cost effectiveness analysis of the systematic and opportunistic programmes and the effect of varying disease prevalence, compliance, and sensitivity and specificity to allow generalisation of our results throughout the NHS.

\section{Methods}

The systematic screening programme uses a mobile screening unit that visits inner city general practices together with a dedicated hospital assessment clinic. ${ }^{16}$ Screening comprises three-field, non-stereoscopic photography using mydriasis; $35 \mathrm{~mm}$ transparencies; and validated grading. The pre-existing opportunistic service used direct ophthalmoscopy and was performed by general practitioners, optometrists, and diabetologists. There was no systematic training, central coordination, or audit, and patients with positive results were assessed in general hospital eye service clinics.

The outcome measure was the detection of sight threatening eye disease, defined as any of the following: moderate preproliferative retinopathy or worse; circinate exudates within the macula; any exudate within 1 disc diameter of the foveola; other diabetes related disease such as vascular occlusion.

\section{Source data}

Data for this analysis were taken from two studies within the Liverpool diabetic eye study. The first was a cross sectional observational study of 320 diabetic patients registered with four general practices who were examined by a consultant ophthalmologist specialising in medical retinal diseases using slit-lamp biomicroscopy (an accepted reference standard for determining need for treatment). ${ }^{8}{ }^{16}$ The second study comprised an analysis of the implementation of systematic screening in Liverpool and included a structured, closed response questionnaire adminis-

\author{
Centre for Health \\ Planning and \\ Management, \\ University of Keele, \\ Keele, Staffordshire \\ ST5 5BG \\ Marilyn James \\ head of health \\ economics (research \\ and development) unit \\ David A Turner \\ research fellow \\ St Paul's Eye Unit \\ Royal Liverpool \\ University \\ Hospitals, Liverpool \\ L7 8XP \\ Deborah M \\ Broadbent \\ clinical assistant \\ Simon P Harding \\ consultant \\ ophthalmologist \\ Department of \\ Diabetes and \\ Endocrinology, \\ Royal Liverpool \\ University Hospitals \\ Jiten Vora \\ consultant \\ diabetologist \\ Correspondence to: \\ M James \\ m.james@keele. \\ ac.uk
}

BMJ 2000;320:1627-31 
tered by trained observers to the first 1363 diabetic patients recruited. ${ }^{17}$ These two studies provided all data except the specificity of the opportunistic programme, which was calculated from a previous study. ${ }^{1}$ We adopted a health service perspective for measurement of costs and benefits.

Four key data variables are necessary to determine overall effectiveness in any screening programme: disease prevalence; compliance; sensitivity and specificity of the screening method; and cost. The disease prevalence applied across both the systematic programme and the opportunistic programme, but the other variables were analysed separately for the two programmes. The overall baseline prevalence of sight threatening eye disease in Liverpool was calculated as $14.1 \%$ from the cross sectional study.

Compliance with systematic screening during data collection (1995-6) was 80\%. The Liverpool study has a current contracted activity of 4000 screen events a year. To achieve this with a compliance of $80 \%, 5000$ screening invitations need to be sent. The cross sectional study showed that the systematic programme had a sensitivity of $89 \%$ (95\% confidence interval $80 \%$ to $98 \%)$ and specificity of $86 \%(82 \%$ to $90 \%){ }^{16}$

Compliance for opportunistic screening was calculated from the questionnaire; 78\% (1059/1363) reported screening in the 12 months before attending for systematic screening. ${ }^{16}$ To accurately compare systematic with opportunistic screening the costs and detection rates were also based on 5000 invitations, but a 78\% compliance produces only 3900 screen events. The sensitivity of opportunistic screening was calculated from the cross sectional study and the questionnaire data. ${ }^{8}$ Seven per cent (22/320) of patients were already under the care of an ophthalmologist for eye disease detected opportunistically. This number was divided by the prevalence $(14.1 \%)$ to give $49 \%$ of patients, and a sensitivity of $63 \%$ was derived by dividing by the proportion who reported opportunistic screening in the previous year (49/78).

The specificities for the various health professionals performing opportunistic screening were taken from Buxton et al (general practitioners $89 \%$, diabetologists 96\%, and optometrists 94\%). ${ }^{1}$ The proportions of patients screened by each class of health professional (obtained from the study questionnaire) were used to derive an overall specificity for the opportunistic programme of $92 \%$.

Costs

We used an ingredient approach because the costs in screening programmes are largely fixed or semifixed; recording individual patient based costings is not helpful in this situation. Capital was given a seven year life and discounted at the test discount rate of $6 \%$. Overhead costs for hospital based activities-grading, administration, and follow up-were set at 10\% (Royal Liverpool University Hospitals Trust finance data).

Costs of systematic screening were calculated on actual resource use at 1996-7 prices for 4000 screen events with additional administrative costs to call nonattendees. Costs of opportunistic screening were calculated for an activity of 3900; with no call-recall system, there are no additional administrative costs. The proportions of patients screened by their general practitioner, diabetologist, or optometrist were identified from the study questionnaire. ${ }^{17}$ Costs of the general practitioner and diabetologist components were calculated by averaging estimates of time spent on direct ophthalmoscopy by six practitioners who regularly did screening. General practitioners' costs per minute including overheads ( 5 minutes at $£ 1.72 / \mathrm{min}$ ) were taken from Netten and Dennett, ${ }^{18}$ with five minutes, additional nursing time per consultation for instilling drops and measuring visual acuity. Diabetologist costs were calculated as a percentage of the cost of a whole outpatient visit for the hospital (standard outpatient cost for $1996-7=£ 55$ ). The optometrist cost was taken as the minimum sight test fee of $£ 13.50$, representing the full cost to the NHS including staff consumables and overheads. The cost of a standard outpatient appointment was also used to cost follow up assessment of patients who had positive results.

Cost effectiveness was calculated as total cost divided by the number of cases detected and incremental cost effectiveness as the extra cost needed to generate each additional true positive result after replacing opportunistic screening by systematic

Table 1 Outcomes of offering screening to 5000 diabetic patients in systematic programme and of screening equivalent cohort opportunistically

\begin{tabular}{lcc} 
Outcome & $\begin{array}{c}\text { Systematic } \\
\text { screening }\end{array}$ & $\begin{array}{c}\text { Opportunistic } \\
\text { screening }\end{array}$ \\
\hline True positive & 502 & 346 \\
\hline False positive & 481 & 268 \\
\hline True negative & 2955 & 3082 \\
\hline False negative & 62 & 203 \\
\hline Total number screened & 4000 & 3900 \\
\hline
\end{tabular}

Table 2 Annual costs of each stage of systematic photographic screening for a cohort of 5000 invited diabetic patients, 4000 of whom attended

\begin{tabular}{lc} 
& Annual cost (£) \\
\hline Photographic screening & 64517 \\
\hline 1.3 whole time equivalent photographer & 20040 \\
\hline 1.0 whole time equivalent auxillary nurse & 10617 \\
\hline 0.5 whole time equivalent clerical worker & 6359 \\
\hline Film & 3994 \\
\hline Stationery & 934 \\
\hline Medical and surgical (drops, sundries, etc) & 2710 \\
\hline Capital charges and depreciation: & \\
\hline Van & 7571 \\
\hline Camera & 5451 \\
\hline Computer & 1908 \\
\hline Camera maintenance contract & 500 \\
\hline Van maintenance & 300 \\
\hline Petrol & 2310 \\
\hline Addition for non-attenders (administration plus stationery) & 1823 \\
\hline Grading & 15739 \\
\hline 0.125 whole time equivalent clinical assistant & 3918 \\
\hline 0.135 whole time equivalent nurse grade $\mathrm{F}$ & 3097 \\
\hline 0.5 whole time equivalent clerical worker & 6359 \\
\hline Stationery & 934 \\
\hline Overheads & 1431 \\
\hline Assessment clinic & 23740 \\
\hline 0.375 whole time equivalent clinical assistant & 11755 \\
\hline 0.135 whole time equivalent nurse grade $F$ & 2534 \\
\hline 0.5 whole time equivalent clerical worker & 6359 \\
\hline Stationery & 1004996 \\
\hline Overheads & \\
\hline External quality control & 2158 \\
\hline & \\
\hline
\end{tabular}


screening. To test the robustness of the study we conducted a sensitivity analysis to determine the effect on cost effectiveness of varying the key variables.

\section{Results}

A baseline prevalence of $14.1 \%$ and a cohort of 5000 patients yield an assumed $705(14.1 / 100 \times 5000)$ true cases of sight threatening eye disease in the target population. Table 1 shows the number of true and false positive and negative results calculated for each programme. Table 2 shows the costs for the components of systematic screening, and table 3 presents costs for opportunistic screening based on the percentage of the sample seen by each type of screener. Total costs were $£ 104996$ for systematic screening and £99981 for opportunistic screening. The cost effectiveness was $£ 209$ and £289 respectively, and incremental cost effectiveness was £32 (table 4).

\section{Sensitivity analysis}

Figure 1 shows the effect of varying the prevalence of sight threatening eye disease on cost effectiveness. If the prevalence falls the cost effectiveness of both programmes falls. At all prevalences the opportunistic programme is less expensive, but the systematic programme is more cost effective than the opportunistic programme.

A two way analysis of the effect on the systematic screening programme of varying sensitivity and specificity within previously reported $95 \%$ confidence limits ${ }^{16}$ gave a value of $£ 237$ for low sensitivity and low specificity $(80 \%, 82 \%)$ and $£ 186$ for high sensitivity and

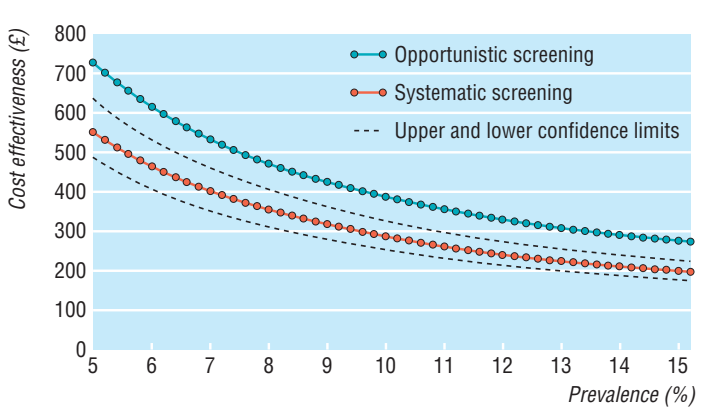

Fig 1 Effect of changing prevalence of sight threatening diabetic eye disease on cost effectiveness of systematic and opportunistic screening programmes

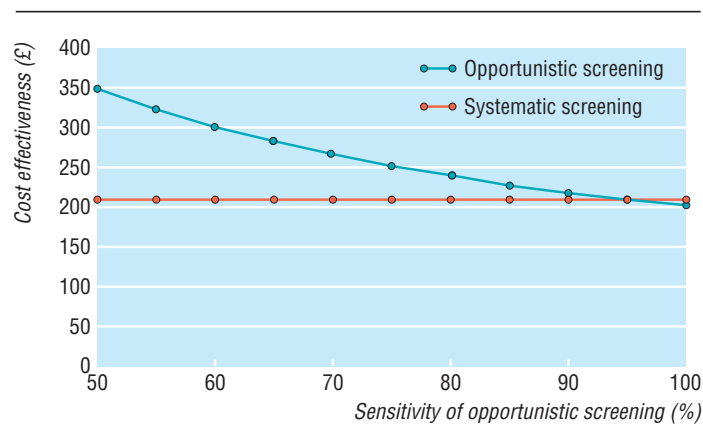

Fig 2 Effect of varying sensitivity of opportunistic screening on cost effectiveness. Cost effectiveness of systematic screening is shown as horizontal line
Table 3 Costs of screening tests extrapolated for opportunistic screening programme for cohort of 3900 diabetic patients from a target population of 5000

\begin{tabular}{lcccc} 
& \multicolumn{3}{c}{ Screener } & \\
\cline { 2 - 4 } & General practitioner & Diabetologist & Optometrist & Total \\
\hline No $(\%)$ screened & $1190(23.8)$ & $1710(34.2)$ & $1720(34.4)$ & 3900 \\
\hline Cost of screening $(£)$ & 12211 & 30780 & 23220 & 66211 \\
\hline Cost of follow up $(£)$ & 11282 & 10398 & 12090 & 33770 \\
\hline Total cost $(£)$ & 23493 & 41178 & 35310 & 99981 \\
\hline
\end{tabular}

Table 4 Cost effectiveness of opportunistic and systematic screening programmes

\begin{tabular}{lccc} 
& $\begin{array}{c}\text { Opportunistic } \\
\text { screenng }\end{array}$ & $\begin{array}{c}\text { Systematic } \\
\text { screening }\end{array}$ & Difference \\
\hline Cost of screening $(£)$ & 99981 & 104996 & 5015 \\
\hline No of true cases detected & 346 & 502 & 156 \\
\hline Cost effectiveness $(£)$ & 289 & 209 & $32^{\star}$ \\
\hline
\end{tabular}

${ }^{*}$ Incremental cost effectiveness of systematic screening.

specificity $(98 \%, 90 \%)$. Systematic screening is more cost effective than opportunistic screening within the $95 \%$ confidence range. Figure 2 shows the effect of varying the sensitivity of opportunistic screening on its cost effectiveness. Cost effectiveness ranged from $£ 350$ to $£ 202$. Opportunistic screening is less cost effective than systematic screening at all levels of its sensitivity up to $95 \%$.

As compliance with systematic screening rises cost effectiveness improves, varying from $£ 487$ for $30 \%$ compliance to $£ 176$ for $100 \%$ compliance. At $54 \%$ compliance the cost effectiveness of systematic screening equals that of opportunistic screening at £289.

Increasing activity to 6000 screens a year raises the total cost for systematic screening to $£ 139856$. The cost per screen event falls from $£ 26$ to $£ 23$, and cost effectiveness improves to $£ 186$. There is a saving of $£ 43$ per true positive case detected when screening systematically rather than opportunistically. Increasing activity to 6000 screens a year raises the total cost for opportunistic screening to $£ 149972$ with no improvement in cost effectiveness. This makes opportunistic screening more expensive than a systematic programme.

\section{Discussion}

We directly compared the costs of pre-existing opportunistic screening with a newly introduced systematic programme. The systematic programme is slightly more expensive than the opportunistic programme but yields 157 extra cases at only $£ 32$ per case.

In an earlier cost effectiveness assessment, Buxton et al studied 3318 screen events in three UK centres using two methods: direct ophthalmoscopy by optometrists, physicians, and general practitioners and single field non-mydriatic polaroid photography. ${ }^{12}$ If their figures are adjusted to 1996-7 prices the cost effectiveness of direct ophthalmoscopy by optometrists is $£ 1057$, hospital physicians £1392, and general practitioners $£ 853-£ 1454$; the costs of hospital and community photographic screening ranged from $£ 670$ to $£ 2084$. Their disappointing results were largely due to suboptimal screening methods and a low prevalence $(5.8 \%)^{2}$

Lairson et al studied the cost effectiveness of four screening methods in the United States. ${ }^{5}$ They also found a large difference between a photographic pro- 
tocol similar to ours (\$295 (£184)) and direct ophthalmoscopy by a technician (\$794), with direct ophthalmoscopy over 2.5 times more expensive than photography.

\section{Applicability}

Our results can be generalised to other British photographic screening programmes. The baseline prevalence is likely to be similar throughout the country, ${ }^{19}$ as is the effectiveness of opportunistic screening. However, accurate data on sensitivity, specificity, and compliance are required to complete an analysis based on our model. Such an analysis would be valuable when applied to other current techniques including dual modality screening, ${ }^{20-22}$ optometry based programmes, ${ }^{23}$ digital photography, ${ }^{24}{ }^{25}$ and automated neural net systems. ${ }^{26}$

Several factors may have influenced our results. Disease prevalence is an important determinant of cost effectiveness, but the systematic screening was always more cost effective than opportunistic screening at all values of sensitivity and specificity within the $95 \%$ confidence limits for our data (fig 1). ${ }^{16}$ Lairson et al reported similar findings. ${ }^{5}$ This is important as prevalence in the screened population will fall with each year of screening: each year the true positive group will comprise patients who develop sight threatening eye disease in that year and a number of people with false negative results from the previous year. After several years the prevalence should approach the underlying incidence of new cases a year.

Cost effectiveness is further influenced by the effectiveness of the screening tool. Varying sensitivity and specificity between the upper and lower 95\% confidence limits in the systematic programme produced only a small variation in cost effectiveness. However, in the opportunistic programme the low sensitivity for direct ophthalmoscopy gave a poor cost effectiveness. Studies of the sensitivity of direct ophthalmoscopy have all reported low rates with general practitioners and untrained physicians, ${ }^{19-11}{ }^{27}$ even after intensive training. ${ }^{28}$ Unacceptably high serious error rates have also been reported with a trained retina specialist. ${ }^{12}$ The best sensitivity reported to date is $65 \%$ with a trained ophthalmologist, ${ }^{16}$ and at this level systematic screening is more cost effective.

Compliance with screening greatly affects cost effectiveness, with higher rates of compliance increasing cost effectiveness. A compliance rate of $80 \%$ was achieved in the second year of the systematic programme, and this may improve with better targeting and education and the implementation of a district diabetes register. However, full coverage is probably impossible because of factors such as death, housebound patients, and high population turnover in an inner city.

Our analysis is based on an annual 5000 invitations yielding 4000 screen events. Increasing the annual activity to full coverage at 6000 screen events increases the cost of systematic screening but confers an $11 \%$ (£23) improvement in cost effectiveness because capital costs do not change. The incremental cost effectiveness becomes negative, indicating a real cost saving.

\section{What is already known on this topic}

Screening for diabetic eye disease can prevent loss of sight

Screening in Britain is currently opportunistic

The cost effectiveness of systematic screening has not been properly evaluated

\section{What this study adds}

Cost effectiveness of systematic screening in primary care using a multiple 45 field photographic protocol was £209 compared with $£ 289$ for an existing opportunistic programme

The incremental cost effectiveness of replacing opportunistic screening with systematic screening was £32

Systematic screening remained more cost effective than opportunistic screening for all values of disease prevalence

\section{Outcome measures}

We have used the number of detected cases as our measure of effectiveness. The use of this proxy measure depends on the inference that correctly and appropriately identified cases can be treated and blindness prevented. Although useful, this kind of measure does not necessarily show the full effectiveness of a programme as it reflects process rather than final outcome. Further work is required to measure cost effectiveness against long term end points such as numbers of patients treated, years of sight saved, quality of life, or numbers of blind registrations. ${ }^{5}$

In conclusion, our cost comparison implies that a purchaser can recover the costs of opportunistic screening by diverting them to systematic screening. In our opinion reallocation of resources is feasible, and purchasers can justify the small increase in costs entailed by introducing systematic screening.

We thank Mr P Kingham of Royal Liverpool University Hospitals Trust finance department for help with costs.

Contributors: SPH, DMB, MJ, and JV conceived the study and wrote the protocol. DAT and MJ performed cost modelling and sensitivity analysis. DMB performed prevalence and compliance analysis and contributed to cost modelling. SPH wrote the manuscript with contributions from MJ, DAT, DMB, and JV. MJ is the guarantor of the study.

Funding: This study was funded by North West Regional grant DIF1.

Competing interests: None declared.

1 Buxton MJ, Sculpher MJ, Ferguson BA, Humphreys JE, Altman JF, Spiegelhalter DJ, et al. Screening for treatable diabetic retinopathy: a comparison of different methods. Diabet Med 1991:8:371-7.

2 Sculpher MJ, Buxton MJ, Ferguson BA, Humphreys JE, Altman JFB, Spiegelhalter DJ, et al. A relative cost-effectiveness analysis of different methods of screening for diabeticretinopathy. Diabetic Med 1991;8:64450

3 Fendrick AM, Javitt JC, Chiang YP. Cost-effectiveness of the screening and treatment of diabetic retinopathy. What are the costs of underutilization? Int J Technol Assess Health Care 1992;8:694-707.

4 Javitt JC, Canner JK, Sommer A. Cost-effectiveness of current approaches to the control of retinopathy in type I diabetics. Ophthalmology 1989;96:255-64

5 Lairson DR, Pugh JA, Kapadia AS, Lorimor RJ, Jacobson J, Velez R. Costeffectiveness of alternative methods for diabetic retinopathy screening. Diabetes Care 1992;15:1369-77.

6 Dasbach EJ, Frybach DG, Newcomb PA, Klein R, Klein BEK Cost-effectiveness of strategies for detecting diabetic retinopathy. Med Care 1991;29:20-39. 
7 Sculpher MJ, Buxton MJ, Ferguson BA, Spiegelhalter DJ, Kirby AJ Screening for diabetic retinopathy: a relative cost-effectiveness analysis of alternative modalities and strategies. Health Econ 1992;1:39-51.

8 Scott JA, Harding SP, Broadbent DM, Vora J. Detecting sight threatening diabetic eye disease in an inner city setting in the UK-the Liverpool diabetic eye study. Invest Ophthalmol Vis Sci 1996;37:S105.

9 Finlay R, Griffiths J, Jackson G, Law D. Can general practitioners screen their own patients for diabetic retinopathy? Health Trends 1991;23:104-5.

10 Awh CC, Javitt JC, Chong LP, Gehrs KM, Gusman GI, Street DA, et al. Ophthalmoscopic diagnosis and referral of diabetic eye disease by Primary Care Physicians. ARVO abstract. Invest Ophthalmol Vis Sci 1993;34:713.

11 Forrest RD, Jackson CA, Yudkin JS. Screening for diabetic retinopathy. Comparison of a nurse and doctor with retinal photography. Diabetes Res 1987;5:39-42.

12 Kinyoun JL, Martin DC, Fujimoto WY, Leonetti DL. Ophthalmoscopy versus fundus photography for detecting and grading diabetic retinopathy. Invest Ophthalmol Vis Sci 1992;33:1888-93.

13 Foulds W, McCuish A, Barrie T, Green F, Scobie IN, Ghafour IM, et al. Diabetic retinopathy in the west of Scotland: its detection and prevalence, and cost-effectiveness of a proposed screening programme. Health Bull 1983;41:318-26.

14 Rohan TE, Frost CD, Wald NJ. Prevention of blindness by screening for diabetic retinopathy: a quantitative assessment. BMJ 1989;299:1198-201.

15 Davies R, Sullivan P, Canning C. Simulation of eye disease to compare screening policies. Br J Ophthalmol 1996;80:945-50.

16 Harding SP, Broadbent DM, Neoh C, White MC, Vora J. Sensitivity and specificity of photography and direct ophthalmoscopy in screening for sight threatening eye disease: the Liverpool diabetic eye study. BMJ 1995:311:1131-5.

17 Briggs MC, Broadbent DM, Harding SP, Vora JP. Primary screening in an inner city-the Liverpool diabetic eye study. Diabet Med 1995;12(suppl 2):S44.

18 Netten A, Dennett J. Unit costs of community care. Canterbury: Personal Social Services Research Unit, University of Kent, 1996.
19 Owens DR, Gibbins RL, Lewis PA, Wall S, Allen JC, Morton R. Screening for diabetic retinopathy by general practitioners: ophthalmoscopy or retinal photography as $35 \mathrm{~mm}$ transparencies? Diabet Med 1998; 15:170-5

20 Ryder B. Screening for diabetic retinopathy. BMJ 1995:311:207-8.

21 O'Hare JP, Hopper A, Madhaven C, Charny M, Purewal TS, Harney B, e al. Adding retinal photography to screening for diabetic retinopathy: a prospective study in primary care. $B M J 1996 ; 312: 679-82$.

22 Jacob J, Stead J, Sykes J, Taylor D, Tooke JE. A report on the use of technician ophthalmoscopy combined with the use of the Canon nonmydriatic camera in screening for diabetic retinopathy in the community. Diabet Med 1995;12:419-25.

23 Leese GP, Tesfaye S, Dengler-Harles M, Laws F, Clark DI, Gill GV, et al. Screening for diabetic eye disease by optometrists using the slit-lamp. $J R$ Coll Physicians 1997;31:65-9.

24 George LD, Halliwell M, Hill R, Aldington SJ, Lusty J, Dunstan F, et al. A comparison of digital and $35 \mathrm{~mm}$ colour transparencies in detecting and grading diabetic retinopathy. Diabetic Med 1998;15:250-3.

25 Ryder REJ, Kong N, Bates AS, Sim J, Welch J, Kritzinger EE. Instant electronic imaging systems are superior to polaroid at detecting sight threatening diabetic retinopathy. Diabet Med 1998;15:254-8.

26 Gardner GG, Keating D, Williamson TH, Elliott AT. Automatic detection of diabetic retinopathy using an artificial neural network: a screening tool. Br J Ophthalmol 1996;80:940-4.

27 Sussman EJ, Tsurias WG, Sarper KA. Diagnosis of diabetic eye disease JAMA 1982;247:3231-4.

28 Gehrs KM, Chong LP, Gusman G, Street DA, Awh C, Cupples H, et al. Can we educate primary care physicians about diabetic retinopathy after graduation? Preliminary results of the diabetic retinopathy education study. Invest Ophthalmol Vis Sci 1993;34:S1182.

\author{
Abstract \\ Objective To determine the frequency of disability in \\ young people and adults admitted to hospital with a \\ head injury and to estimate the annual incidence in \\ the community. \\ Design Prospective, hospital based cohort study, with \\ one year follow up of sample stratified by coma score. \\ Setting Five acute hospitals in Glasgow. \\ Subjects 2962 patients (aged 14 years or more) with \\ head injury; 549 (71\%) of the 769 patients selected for \\ follow up participated. \\ Main outcome measures Glasgow outcome scale and \\ problem orientated questionnaire. \\ Results Survival with moderate or severe disability \\ was common after mild head injury $(47 \%, 95 \%$ \\ confidence interval $42 \%$ to $52 \%$ ) and similar to that \\ after moderate $(45 \%, 35 \%$ to $56 \%)$ or severe injury \\ $(48 \%, 36 \%$ to $60 \%)$. By extrapolation from the \\ population identified ( $90 \%$ of whom had mild \\ injuries), it was estimated that annually in Glasgow \\ (population 909 498) 1400 young people and adults \\ are still disabled one year after head injury. \\ Conclusion The incidence of disability in young \\ people and adults admitted with a head injury is \\ higher than expected. This reflects the high rate of \\ sequelae previously unrecognised in the large number \\ of patients admitted to hospital with an apparently \\ mild head injury.
}

\section{Introduction}

More than 150000 patients with a head injury are known to be admitted to hospital each year in the United Kingdom, but estimates of the frequency of subsequent disability in such patients range from two or three to 45 per 100000 population per year (see table A on website). ${ }^{1-4}$ This variation reflects limitations in previous studies, particularly the lack of data on patients with an apparently mild injury, who account for $80 \%$ of admissions. ${ }^{1}$ One review concluded that "given the human and economic importance of head injury, there is an urgent need to acquire more epidemiological information on the management and outcome of head injury of all grades of severity." We aimed to identify a representative cohort of young people and adults admitted to hospital with a head injury within a geographically identified population, determine their outcome, and estimate the incidence of disabled survivors in the community one year later.

\section{Subjects and methods}

\section{Study protocol}

Approval for our study was obtained from ethics committees of the five general hospitals to which patients with acute head injuries are admitted in Glasgow. Cooperation with ward and accident and emergency staff was also secured. Between February 1995 and February 1996, research staff visited each hospital fre-
Department of Neurosurgery, University of Glasgow, Southern General NHS Trust Glasgow G51 4TF Sharon Thornhill research assistant Graham M Teasdale professor

Department of Community Health Sciences, University of Edinburgh, Edinburgh EH8 9AG

Gordon D Murray professor of medical statistics

continued over

BMJ 2000;320:1631-5

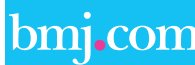

Additional tables and the problem orientated questionnaire appear on the BMJ's website 